\title{
Theoretical Study of Diels-Alder Reaction of But-3-en-2-one with Hexa-1,2,4-triene: A Density Functional Theory Study
}

\author{
Rezan J. Hassan ${ }^{1,2}$ and Hassan H. Abdallah ${ }^{1}$ \\ ${ }^{1}$ Department of Chemistry, College of Education, Salahaddin University-Erbil, \\ Erbil 44001, Kurdistan Region - F.R. Iraq \\ ${ }^{2}$ Department of Chemistry, College of Science, Salahaddin University-Erbil, \\ Erbil 44001, Kurdistan Region - F.R. Iraq
}

\begin{abstract}
The Diels-Alder reaction between but-3-en-2-one with hexa-1,2,4-triene was studied using density functional theory method at B3LYP-D3/6-311++G(d,p) level of theory. The geometries of the transition states were determined. Moreover, calculations of the vibrational frequencies permitted computation of the activation enthalpies and entropies. The computational results show that the cycloadducts from trans conformer have the lower relative energies $(-46.48$ and $-47.50 \mathrm{kcal} / \mathrm{mol})$ as compared to the cis conformer of cycloadducts $(-44.45$ and $-45.87 \mathrm{kcal} / \mathrm{mol})$. The global reactivity indices were analyzed at the ground state of reactants to predict the reactivity of the studied organic molecules in the cycloaddition reactions. The electronic chemical potential of hexa-1,2,4-trien found to be than but-3-en-2-one, which indicates that the net charge transfer will be from hexa-1,2,4-trien toward the electron-deficient but-3-en-2-one reactant.
\end{abstract}

Index Terms-Cycloaddition, density functional theory calculation, Diels-Alder reaction, mechanism.

\section{INTRODUCTION}

Synthesis of complex cyclic compounds is necessary for the development of functional materials such as biologically active compounds, so, very recently, computational studies on cycloaddition reactions have been the subject of a number of researches due to their wide applications on synthetic organic compounds (Mohammad-Salim, et al., 2020; MohammadSalim and Abdallah, 2019; Salim, Abdallah and Ramasami, 2018a; Salim, Abdallah and Ramasami, 2018b). Among the cycloaddition reactions, the formation of compounds with an unsaturated six-membered ring through the addition of a conjugated diene to a double or triple bond is known as

ARO-The Scientific Journal of Koya University Volume. VIII, No.1(2020), Article ID: ARO.10632, 5 pages DOI: $10.14500 /$ aro. 10632

Received 08 February 2020; Accepted: 26 May 2020

Regular research paper: Published 12 June 2020

Corresponding author's, e-mail: hassan.abdullah@su.edu.krd

Copyright (C) 2020 Rezan J. Hassan and Hassan H. Abdallah. This is an open access article distributed under the Creative Commons Attribution License. the Diels-Alder (D-A) reaction. Since the discovery of this reaction, more than 17,000 articles have been published in relation to synthesis, mechanism, and theoretical aspects of the reaction, and about half of these appeared in the 19902000 decade (Fringuelli and Taticchi, 2002).

Diels-Alder cycloaddition is one of the most significant and useful tools available in synthetic chemistry (KalKoshvandi and Heravi, 2019). This organic reaction is widely used to build six-member rings with a maximum of four stereogenic centers on a regal and stereo-controlled route (Džambaski, et al., 2019; Zhang, et al., 2019). with the potential formation of carbon-carbon, carbon-heteroatom, and heteroatom-heteroatom bonds (Baeza, 2018; Boger and Weinreb, 2012; Siah, Leung and Mok, 1995).

The mechanistic study of the D-A reaction proceeds through concerted mechanism, usually but not necessarily through a synchronous. Experimental results support a concerted mechanism, whereas computational calculations depend on the method used, for example, semi-empirical calculations (for example, AM1 and PM3) predict a stepwise mechanism, whereas density functional theory (DFT) calculations with B3LYP functional and ab-initio calculations using MP2 and coupled-cluster methods favor a concerted mechanism rather than stepwise mechanism (Jursic and Zdravkovski, 1994; Mohammad-Salim and Abdallah, 2019; Pham and Houk, 2014). In the late $80 \mathrm{~s}$, experimental and theoretical evidence converged on a synchronous mechanism. In addition, zwitterionic intermediates have been reported for reactions of 1,3-butadienes with strong demand electronics, for example, 1,1-dimethoxy-1,3-butadiene with electronically poor dienophiles (Carey and Sundberg, 2007).

Asymmetrically substituted dienes and dienophiles give a mixture of two regioisomers, and the regioselectivity in the reactions of disubstituted dienes and with a greater degree of substitution depends on the electronic properties and the relative position of the substituents. In this study, the mechanism and regioselectivity of the D-A reaction of hexa-1,2,4-trien and but-3-en-2-one was studied. To the best of our knowledge, the reaction has not been studied neither experimentally nor theoretically. Therefore, the aim of this 
paper is to suggest the mechanism of the studied reaction using DFT method. The mechanism of the reaction is shown in Scheme 1.

\section{Computational Methods}

All calculations in the present work have been done using Gaussian 09 package (Frisch, et al., 2009). DFT method has been proven to be a suitable method for the study of cycloaddition reactions and is achieved in this work as well (Khabashesku, Kudin and Margrave, 2001; Lemal, 2017; Parr and Weitao, 1989). B3LYP functional is used throughout in combination with 6-311++G(d,p) basis set (Ditchfield, Hehre and Pople, 1971; Lee, Yang and Parr, 1988). We also considered the D3 correction to take into account for the role of dispersion energies in the stability of the complexes and intermediates (Grimme, et al., 2010). Frequency calculations were performed to ensure that a transition state has only one negative frequency and a local minimum has no negative frequencies. Intrinsic reaction coordinate computations were carried out to confirm that the reactants and products are connected through the transition states (Fukui, 1970). All energies and thermodynamic parameters reported in this paper were obtained from the frequency calculations at the same level of theory. The CYLview software was used as a graphical interface (Legault, 2009).

The global electrophilicity index $(\omega)$ is obtained in terms of the electronic chemical potential $(\mu)$ and the chemical hardness $(\eta)$ using the following simple expression (Parr, Szentpály and Liu, 1999):

$$
\omega=\frac{\mu^{2}}{2 \eta}
$$

The chemical hardness $(\eta)$ and the electronic chemical potential $(\mu)$ quantities may be approached in terms of the one electron energies of highest occupied molecular orbital (HOMO) and lowest unoccupied molecular orbital (LUMO), $\varepsilon_{\mathrm{H}}$ and $\varepsilon_{\mathrm{L}}$, as (Parr and Pearson, 1983; Parr and Weitao, 1994):

$$
\begin{aligned}
& \eta \approx \varepsilon_{L}-\varepsilon_{H} \\
& \mu \approx \frac{\varepsilon_{H}+\varepsilon_{L}}{2}
\end{aligned}
$$

The relative nucleophilicity index $(\mathrm{N})$ obtained based on the energies of HOMO within the scheme of Kohn-Sham (Kohn and Sham, 1965). This quantity can be defined using Equation (4). Where TCE is tetracyanoethylene and is chosen due to its lowest HOMO energy as a reference (Domingo, Chamorro and Pérez, 2008).

$$
N=E_{H O M O(N u)}-E_{H O M O(T C E)}
$$

\section{Results AND Discussion}

The D-A reaction of hexa-1,2,4-trien (R1) with but-3en-2-one (R2) gives the corresponding products P1a, P1b, P2a, and P2b passing through TS1a, TS1b, TS2a, and TS2b, respectively, as sketched in Scheme 1. Fig. 1 shows the energy profiles of studied reactions. These energy profiles were determined at the B3LYP-D3/6-311++G(d,p)

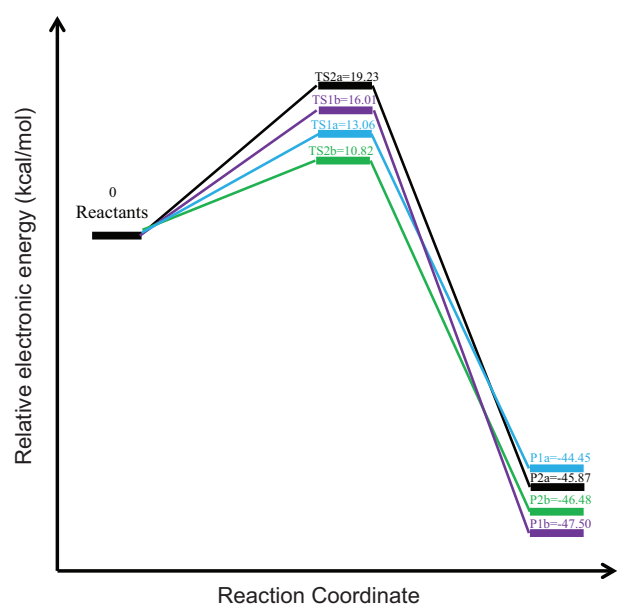

Fig. 1. Energy profile for the [4+2] cycloaddition reaction of hexa-1,2,4trien (R1) with but-3-en-2-one (R2) using B3LYP-D3/6-311++G(d,p) level of theory. The energies are given relative to reactants $(\mathrm{kcal} / \mathrm{mol})$.

level of theory. The reactions occur through a concerted mechanism.

Fig. 1 shows that there is a significant lowering of the activation energy from cis transition state TS2a to trans $\mathrm{TS} 2 \mathrm{~b}$, around $9 \mathrm{kcal} / \mathrm{mol}$, and moderate lowering from trans transition state TS1b to cis TS1a, about $3 \mathrm{kcal} / \mathrm{mol}$. It is notable to that the cycloadducts from trans conformer, $\mathrm{P} 1 \mathrm{~b}$ and $\mathrm{P} 2 \mathrm{~b}$, have the lower relative energies as compared to the cis conformer of cycloadducts, P1a and P2a. This indicated that the trans cycloadducts are more stable than the cis cycloadducts.

Four transition states, TS1a, TS2a, TS1b, and TS2b, as sketched in Scheme 1, were obtained from the reaction of R1 with R2. The geometries of these transition states are given in Fig. 2. The studied reactions undergo cycloaddition through highly asynchronous transition states. In all cases, the length of the formed $\mathrm{C}-\mathrm{C}$ bond with the ketone function is longer than the other formed $\mathrm{C}-\mathrm{C}$ bond. This is due to the presence of carbonyl group in the dienophile as an electronwithdrawing group. The transition state TS1a has smaller degree of asynchronicity and TS2a has the larger degree of asynchronicity among the other transition states.

The thermodynamic parameters for the reaction of $\mathrm{R} 1$ with $\mathrm{R} 2$ in the gas phase at $1 \mathrm{~atm}$ and $298.15 \mathrm{~K}$ with B3LYP$\mathrm{D} 3 / 6-311++\mathrm{G}(\mathrm{d}, \mathrm{p})$ method are collected in Table I. The activation enthalpies range from 9.85 to $18.11 \mathrm{kcal} / \mathrm{mol}$. It is worth to realize that the activation enthalpies reached the lower value for trans transition state TS2b and highest value cis TS2a, whereas opposite trends were found for TS1a and TS1b this is due to the stereoselectivity in transition states and products. The Gibbs free energies for all products are found to be negative and very close to each other, which indicate that pathways have the same route and no side reactions were found (Kaka, et al., 2019). The enthalpies for products were also found to be negative that indicate that the reactions are possible to occur. The enthalpies for trans products $\mathrm{P} 1 \mathrm{~b}$ and $\mathrm{P} 2 \mathrm{~b}$ are lower than the cis products, which refer to the more stability of trans products than cis products. 


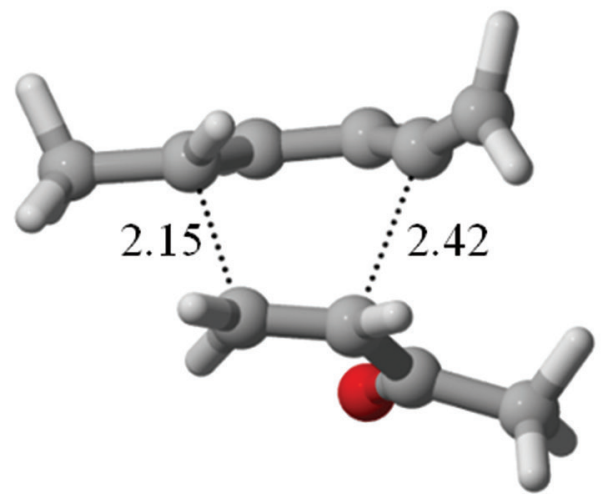

TS1a

$E_{a}=13.06$

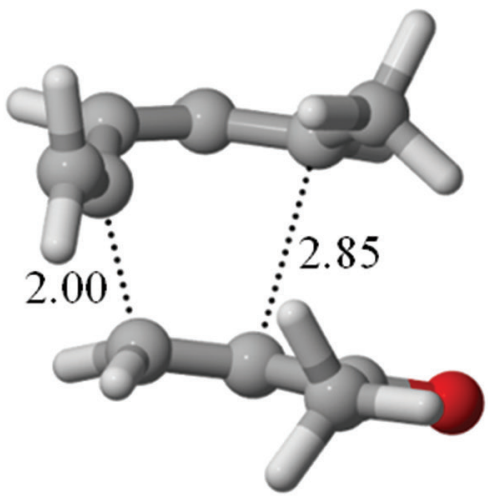

TS2a

$E_{a}=19.23$

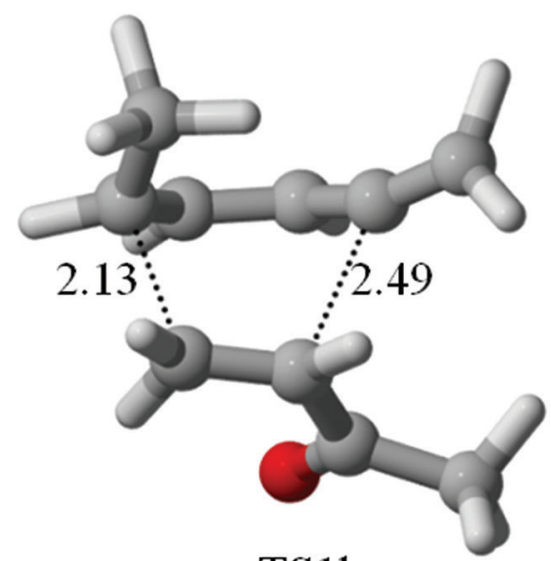

TS1b

$E_{a}=16.01$

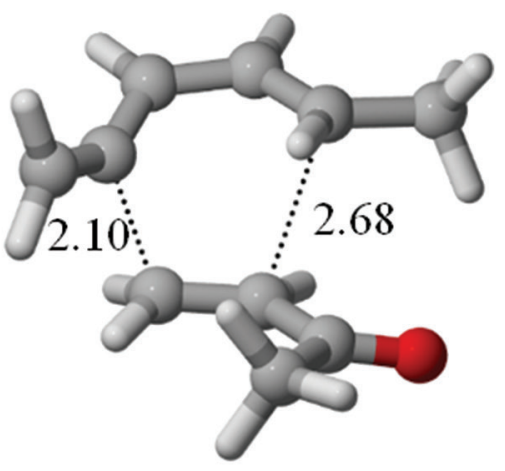

TS2b

$E_{a}=10.82$

Fig. 2. Optimized geometries of the transition states involved in the [4+2] cycloaddition reactions of hexa-1,2,4-trien (R1) with but-3-en-2-one (R2) using B3LYP-D3/6-311++G(d,p) level of theory. The energy $\left(\mathrm{E}_{\mathrm{a}}\right)$, in $\mathrm{kcal} / \mathrm{mol}$, is given relative to reactants.

TABLE I

Thermodynamic Parameters For Transition States And Products At B3LYP-D3/6-311++G(D,P) LeVEL OF TheORY IN (KCAL/MOLE) For $\Delta$ H AND $\Delta \mathrm{G}$ AND IN (CAL/MOL.K) FOR $\Delta \mathrm{S}$

\begin{tabular}{lccc}
\hline \hline Compound & $\Delta \mathbf{H}$ & $\Delta \mathbf{G}$ & $\Delta \mathbf{S}$ \\
\hline P1a & -46.19 & -29.40 & -56.31 \\
P1b & -49.16 & -33.09 & -53.93 \\
P2a & -47.54 & -31.15 & -54.96 \\
P2b & -48.20 & -32.05 & -54.14 \\
TS1a & 12.07 & 27.15 & -50.58 \\
TS1b & 15.04 & 30.26 & -51.05 \\
TS2a & 18.11 & 33.73 & -52.39 \\
TS2b & 9.85 & 24.74 & -49.94 \\
\hline \hline
\end{tabular}

From the observed thermodynamic results that the $\mathrm{P} 1 \mathrm{~b}$ is preferred thermodynamically, whereas $\mathrm{P} 2 \mathrm{~b}$ is preferred kinetically since it has lower activation energy.

In the D-A reaction, predictions of reactivity and selectivity are normally based on the strength of a single FMO interaction between the diene and the dienophile, dienophiles with conjugating groups are usually good for D-A reactions. Dienes react rapidly with electrophiles because their HOMOs are relatively high in energy, but simple alkenes have relatively high-energy LUMOs and do not react well with nucleophiles. The most effective modification is to lower the alkene LUMO energy by conjugating the double bond with an electron-withdrawing group such as carbonyl or nitro. This type of D-A reaction, involving an electronrich diene and an electron-deficient dienophile, is referred to as a D-A reaction with normal electron demand. The HOMO and LUMO energies for all products at B3LYP$\mathrm{D} 3 / 6-311++\mathrm{G}(\mathrm{d}, \mathrm{p})$ level of theory are listed in Table II. The table shows that cis products have narrower energy gaps than trans products. This indicates that the trans products are more stable than the others. The trans product $\mathrm{P} 1 \mathrm{~b}$ has wider energy gap than trans product $\mathrm{P} 2 \mathrm{~b}$. Such results indicate that the trans product $\mathrm{P} 1 \mathrm{~b}$ is more stable among trans products. The results from the analysis of molecular orbitals were found to be consistence with the results obtained from the thermodynamic parameters.

The global reactivity indices defined within the conceptual DFT are a powerful tool to study the reactivity in polar cycloaddition reactions (Mohammad-Salim, 


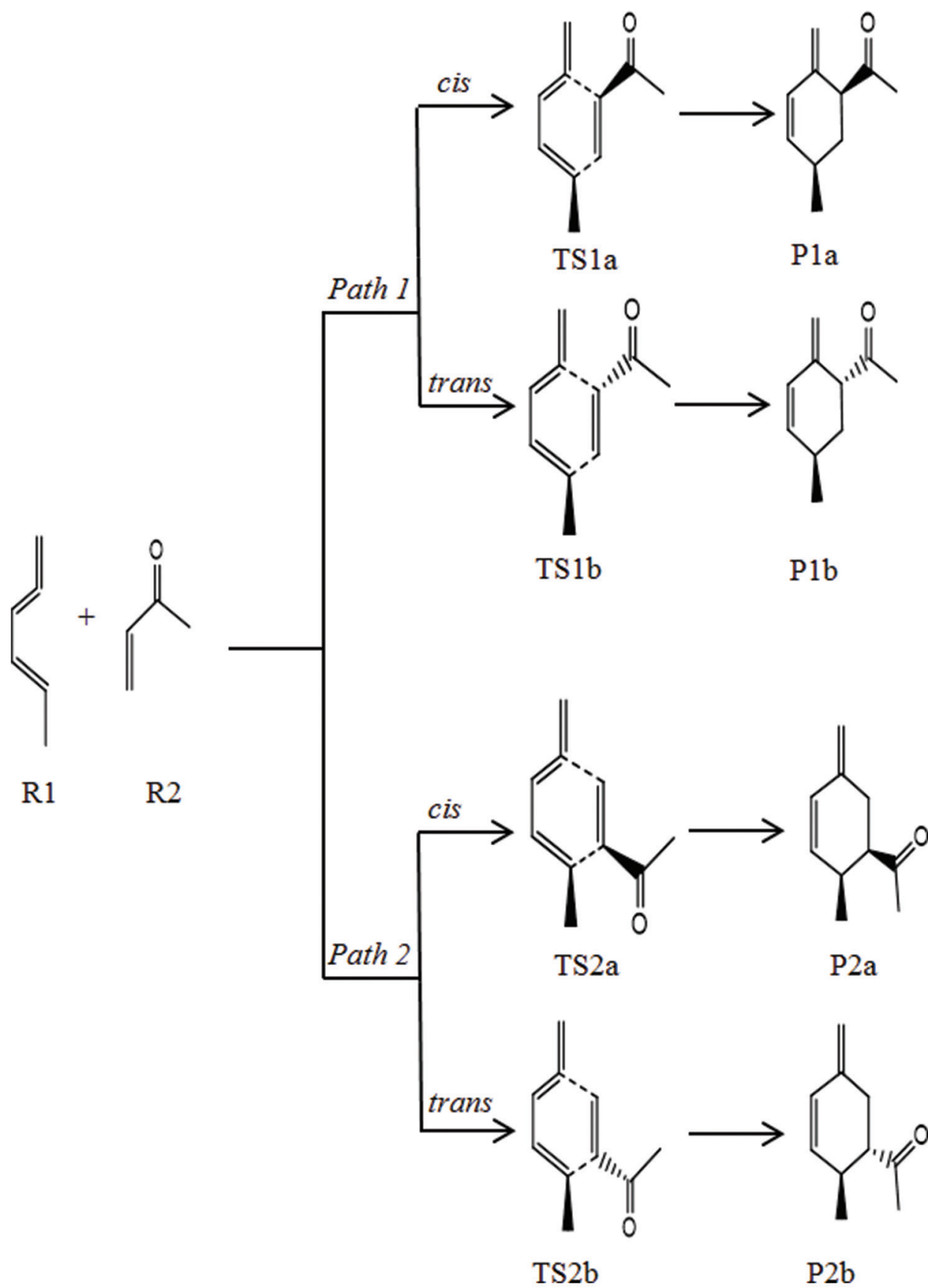

Scheme 1. Proposed reaction mechanism paths for the [4+2] cycloaddition reaction of but-3-en-2-one (R2) and hexa-1,2,4-trien (R1).

TABLE II

HOMO Energies, LUMO Energies, ANd Energy Gap (In EV Unit) For Reactants And Products At B3LYP-D3/6-311++G(D,P) Level Of Theory

\begin{tabular}{lccc}
\hline \hline Compound & HOMO & LUMO & Energy gap \\
\hline P1a & -6.41 & -1.21 & 5.19 \\
P1b & -6.44 & -0.99 & 5.45 \\
P2a & -6.36 & -1.17 & 5.20 \\
P2b & -6.37 & -1.08 & 5.29 \\
\hline \hline
\end{tabular}

et al., 2020). The static global properties, namely, chemical hardness $(\eta)$, global nucleophilicity $(\mathrm{N})$, global electrophilicity $(\omega)$, and electronic chemical potential $(\mu)$ for all reactants in $\mathrm{eV}$ are listed in Table III. The electronic chemical potential of $\mathrm{R} 1(\mu=-3.56)$ is higher than $\mathrm{R} 2$,
TABLE III

The Chemical Hardness (H), Electronic Chemical Potential $(\mu)$, Global

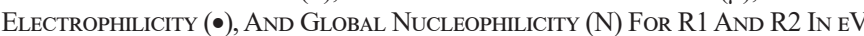

\begin{tabular}{lcccc}
\hline \hline Compound & $\boldsymbol{\eta}$ & $\boldsymbol{\mu}$ & $\boldsymbol{\omega}$ & $\mathbf{N}$ \\
\hline $\mathrm{R} 1$ & 5.16 & -3.56 & 1.23 & 3.35 \\
$\mathrm{R} 2$ & 5.14 & -4.61 & 2.06 & 2.31 \\
\hline \hline
\end{tabular}

which indicates that the net charge transfer will be from R1 towards the electron-deficient $\mathrm{R} 2$ reactant. The $\omega$ for $\mathrm{R} 1$ is $1.23 \mathrm{eV}$ that falls in the range of moderate electrophiles. However, the $\mathrm{N}$ for $\mathrm{R} 1$ is $3.35 \mathrm{eV}$, which falls in the range of strong electrophiles within the global nucleophilicity and electrophilicity. 


\section{CONCLUSION}

DFT method is used to investigate the Diels-Alder reaction between hexa-1,2,4-trien (R1) with but-3-en-2-one (R2) at B3LYP-D3/6-311++G(d,p) level of theory. The concerted mechanism was studied and the geometries of the transition states were determined. The electronic energetic results show that the cycloadducts from trans conformer are more stable than the cis cycloadducts. The global reactivity indices were analyzed at the ground state of reactants to predict the reactivity of the studied organic molecules in the cycloaddition reactions and the results indicate that the net charge transfer will be from hexa-1,2,4-trien toward the electron-deficient but-3-en-2-one reactant.

\section{REFERENCES}

Baeza, A., 2018. Stereogenic Centers. Multidisciplinary Digital Publishing Institute, Basel, Switzerland.

Boger, D.L., and Weinreb, S.M., 2012. Hetero Diels-Alder Methodology in Organic Synthesis, Elsevier, Amsterdam, Netherlands.

Carey, F.A. and Sundberg, R.J., 2007. Advanced organic chemistry: part A: structure and mechanisms. Springer Science \& Business Media

Ditchfield, R., Hehre, W.J., and Pople, J.A., 1971. Self-consistent molecularorbital methods. IX. An extended gaussian-type basis for molecular-orbital studies of organic molecules. The Journal of Chemical Physics, 54(2), pp.724728.

Domingo, L.R., Chamorro, E., and Pérez, P., 2008. Understanding the reactivity of captodative ethylenes in polar cycloaddition reactions. A theoretical study. The Journal of Organic Chemistry, 73(12), pp.4615-4624.

Džambaski, Z., Tzaras, D.I., Lee, S., Kokotos, C.G., and Bondzic, B.P., 2019. Enantioselective organocatalytic enamine $\mathrm{C}-\mathrm{H}$ oxidation/diels-alder reaction. Advanced Synthesis and Catalysis, 361(8), pp.1792-1797.

Fringuelli, F., and Taticchi, A., 2002. The Diels-Alder Reaction: Selected Practical Methods. Wiley, Hoboken, New Jersey.

Frisch, M.J., Trucks, G.W., Schlegel, H.B., Scuseria, G.E., Robb, M.A., Cheeseman, J.R., Scalmani, G., Barone, V., Petersson, G.A., Nakatsuji, H., Li, X., Caricato, M., Marenich, A.V., Bloino, J., Janesko, B.G., Gomperts, R., Mennucci, B., Hratchian, H.P., Ortiz, J.V., Izmaylov, A.F., Sonnenberg, J.L., Williams, Ding, F., Lipparini, F., Egidi, F., Goings, J., Peng, B., Petrone, A., Henderson, T., Ranasinghe, D., Zakrzewski, V.G., Gao, J., Rega, N., Zheng, G., Liang, W., Hada, M., Ehara, M., Toyota, K., Fukuda, R., Hasegawa, J., Ishida, M., Nakajima, T., Honda, Y., Kitao, O., Nakai, H., Vreven, T., Throssell, K., Montgomery Jr., J.A., Peralta, J.E., Ogliaro, F., Bearpark, M.J., Heyd, J.J., Brothers, E.N., Kudin, K.N., Staroverov, V.N., Keith, T.A., Kobayashi, R., Normand, J., Raghavachari, K., Rendell, A.P., Burant, J.C., Iyengar, S.S., Tomasi, J., Cossi, M., Millam, J.M., Klene, M., Adamo, C., Cammi, R., Ochterski, J.W., Martin, R.L., Morokuma, K., Farkas, O., Foresman, J.B., and Fox, D.J., 2009, Gaussian 09 B.01, Gaussian, Inc., Wallingford, CT.

Fukui, K., 1970. Formulation of the reaction coordinate. The Journal of Physical Chemistry, 74(23), pp.4161-4163.

Grimme, S., Antony, J., Ehrlich, S., and Krieg, H., 2010. A consistent and accurate $\mathrm{ab}$ initio parametrization of density functional dispersion correction (DFT-D) for the 94 elements H-Pu. The Journal of Chemical Physics, 132(15), p.154104.

Jursic, B.S., and Zdravkovski, Z., 1994. Comparison of AM1 and PM3 semiempirical to ab initio methods in the study of Diels-Alder reactions of butadiene and cyclopentadiene with cyanoethylenes. Journal of Molecular Structure: THEOCHEM, 309(3), pp.249-257.

Kaka, K.N., Taher, S.G., Hamad, W.M., and Ibrahim, A.H., 2019. Synthesis of new series of pyrazoline, and study their kinetics and reaction mechanism.
ARO-The Scientific Journal of Koya University, 7(2), pp.5-13.

Kal-Koshvandi, A.T., and Heravi, M.M., 2019. Applications of Dainshefsky's dienes in the asymmetric synthesis of aza-diels-alder reaction. The Chemical Record, 19(2-3), pp.550-600.

Khabashesku, V.N., Kudin, K.N., and Margrave, J.L., 2001. Density functional theoretical studies of [2+2] cycloaddition of simple transient silenes and germenes to ethylene, formaldehyde, and thioformaldehyde, and vibrational analysis of spectra of reactants and cyclic products. Russian Chemical Bulletin, 50(1), pp.20-28.

Kohn, W., and Sham, L.J., 1965. Self-consistent equations including exchange and correlation effects. Physical Review, 140(4A), pp.1133-1138.

Lee, C., Yang, W., and Parr, R.G., 1988. Development of the colle-salvetti correlation-energy formula into a functional of the electron density. Physical Review B, 37(2), pp.785-789.

Legault, C. 2009, CYLview 1.0. Université de Sherbrooke, Sherbrooke.

Lemal, D.M., 2017. Pathways for concerted [2+2] cycloaddition to cumulenes. The Journal of Organic Chemistry, 82(24), pp.13012-13019.

Mohammad, S.H., and Abdallah', H., 2019. Theoretical study for the [2+2] cycloaddition reaction mechanism of ketenes and their derivatives. Oriental Journal of Chemistry, 35, pp.1550-1556.

Mohammad-Salim, H., Hassan, R., Abdallah, H.H., and Oftadeh, M., 2020. The theoretical study on the mechanism of [3+2] cycloaddition reactions between $\alpha, \beta$-unsaturated selenoaldehyde with nitrone and with nitrile oxide. Journal of the Mexican Chemical Society, 64(2), p.20.

Mohammad-Salim, H.A., Abdallah, H.H., Maiyelvaganan, K.R., Prakash, M., and Hochlaf, M., 2020. Mechanistic study of the [2+2] cycloaddition reaction of cyclohexenone and its derivatives with vinyl acetate. Theoretical Chemistry Accounts, 139(2), p.19.

Mohammad-Salim, H.A., and Abdallah, H.H., 2019. Theoretical study of the [4+2] cycloaddition reaction of trifluoroethylene with five-membered chalcogens heterocyclic compounds. 7(2), p.9.

Parr, R.G. and Weitao, Y., 1989, Density-Functional Theory of Atoms and Molecules. Oxford University Press, Oxford.

Parr, R.G., and Pearson, R.G., 1983. Absolute hardness: Companion parameter to absolute electronegativity. Journal of the American Chemical Society, 105(26), pp.7512-7516.

Parr, R.G., and Weitao, Y., 1994. Density-Functional Theory of Atoms and Molecules. Oxford University Press, Oxford.

Parr, R.G., Szentpály, L.V., and Liu, S., 1999. Electrophilicity index. Journal of the American Chemical Society, 121(9), pp.1922-1924.

Pham, H.V., and Houk, K.N., 2014. Diels alder reactions of allene with benzene and butadiene: Concerted, stepwise, and ambimodal transition states. The Journal of Organic Chemistry, 79(19), pp.8968-8976.

Salim, H.A.M., Abdallah, H.H., and Ramasami, P., 2018a. Stereoselectivity and regioselectivity of the cycloaddition dimerization of allyl 3-(2-pyridyl) acrylate and allyl 3-(2-pyrryl) acrylate: DFT Calculations. IOP Conference Series: Materials Science and Engineering, 454, p.012049.

Salim, H.M., Abdallah, H.H., and Ramasami, P., 2018b. Mechanism and Thermodynamic Parameters of Paternò-Büchi Reaction of Benzene and Furan: DFT Study. Conference Paper, pp.415-419.

Siah, S.Y., Leung, P.H., and Mok, K.F., 1995. Palladium-complex-promoted asymmetric Diels-Alder reaction: Stereoselective synthesis of a new sulfinylsubstituted phosphine ligand containing three carbon, one phosphorus and one sulfur stereogenic centres. Journal of the Chemical Society, Chemical Communications, 17, pp.1747-1748.

Zhang, H., Liu, G., Guan, X., Gao, J., Qin, X., Jiang, G., Sun, D., Zhang, G., and Zhang, S., 2019. Asymmetric synthesis of triaryl-substituted chromans with multiple stereogenic centers by [4+2] cycloaddition reaction. European Journal of Organic Chemistry, 43, pp.7264-7268. 